\title{
Deception as a Conflict Management Technique Scale: A Preliminary
}

\author{
Analysis \\ Tehzeeb Sakina * Anila Amber Malik ${ }^{\dagger}$
}

\begin{abstract}
The current study was undertaken to develop a self-reporting scale on the perceptions and the uses of deception, both in general and as a conflict management technique. The study was initiated with Item Pool Generation followed by Data Collection which further leads towards Item Selection and finally the reliability and validity assessments. For data collection, a random sample of 408 individuals was drawn and administered with 50-item pool to carry out the item selection. For reliability assessment, a sample of 103 individuals on random basis were derived for the establishment of test-retest reliability. For validity assessment, 135 individuals' random sample was extracted and administered with a battery of tests for ascertaining construct validity. The results of Item-total correlation was calculated and 35 items were selected at 0.05 level of significance. The internal consistency of Deception as Conflict Management Technique Scale (DCMTS) was calculated at 0.896 Cronbach alpha level. Exploratory factor analysis was carried out using varimax rotation. Psychometric reliability and validity assessments concluded that the 35-item scale has significant test-retest reliability and high correlation values are reported for both convergent and discriminant validity. The study further elaborated on the theoretical understanding and implementation of the DCMTS along with its limitations and implications.
\end{abstract}

Keywords: Deception, Conflict Management, Scale development, exploratory factor analysis, reliability, construct validity.

\section{Introduction}

Our mind is everything! WE become what we think! And our thinking gets reflected in our actions. Human nature has what is commonly said, a good side and a bad (dark) side. What makes the difference between the good and the bad is the intention behind the action. An action should not be seen in isolation; as the intention behind the action is what reveals the true man. It is a matter of choice that an individual make - to be good or bad! Moreover, this choice is subjective in interpretation too - what's good and bad for an individual can be vice versa with some other person.

An intention to do good or bad is what outlines how we are going to respond in a particular situation. And also how people perceive us as to what we truly are. For this reason, we try to manage our impression in the eyes of ourselves and others. We may do this by trying to fake our impression or hiding our true intention in order to achieve our desired goals. Simply put we tend to deceive ourselves as well as others! Deception can

*PhD Scholar, Department of Psychology, University of Karachi, Pakistan. E-mail: tehzeebamir@yahoo.com

† Professor, Department of Psychology, University of Karachi, Pakistan. 
said to be a deep rooted intention in any situation.

Deception is a universal phenomenon. Its presence can be found everywhere, whether in social interactions, work places, intra personal (self), or conflict situations (Ekman, 2009). On average, US adults have been found to be lying 1.65 lies per day (Serota, Levine, \& Boster, 2010). An interesting study reports that people can tell two lies in ten minutes (Feldman, Forrest, \& Happ, 2002). More than $80 \%$ of candidates have been found to be lying in their job interviews (Weiss \& Feldman, 2006). Work places report a high number of uses of deception in daily tasks, where managers make unfounded claims that they can detect such deception (Robie, Tuzinski, \& Bly, 2006). Specific behavioral \& physical cues for deception have been under study for a long time. Generally it has been found that deceivers show signs of nervousness because of the fear, worry or guilt of being caught, but similar signs can be shown by candidates due to usual pressures of interview setting (Vrij, Akehurst, \& Knight, 2006; Zuckerman, Koestner, \& Driver, 1981). Humans tend to deceive in situations where the outcome is valuable \& significant, yet uncertain to them. As in a conflict situation, the reward is dependent on the outcome; thus the probability to deceive may be higher.

The concept and usage of defense mechanisms given by Freud (2014) could be conceptualized being similar to self-deception \& deceiving others. Use of socially approved defense mechanisms (Furnham, 2012) have found to be helpful for one's mental wellbeing and that too in the long run (Zhang \& Guo, 2017). Mental wellbeing is what (C. R. Rogers, 1959; C. Rogers, 2008) concept of achieving congruence between Real \& Ideal Self talked about. The thinking pattern which organizes information in our minds is what is called a schema by cognitive psychologists. Our actions are outcome of the schema we carry of ourselves and also of what others think about us (Pietromonaco \& Barrett, 2000; Siefert \& Porcerelli, 2015). Taking this concept of mental wellbeing in the light of these grounded theories, one can conclude that usage of defense mechanisms, the process of achieving congruence, individuals either tend to deceive themselves or others. While doing so, their actions are determined by this deep intention of deceiving which is covert in nature (Hirsh \& Kang, 2016).

Conflicts are inevitable in every sphere of life. Conflict can be some minor differences of opinion, but the outcome significance can influence the intentions of the parties involved in the conflict. In the process of conflict, how the person perceives others and himself which decide how he is going to act is of vital importance that (Stephen, Dixon, $\&$ Isenhower, 2009). Ideally, on a positive note, both the parties need to focus on the mutually beneficial outcomes of the conflict i.e. win-win situation. Whereas conflict can be harmful as parties involved feel uncertain for the outcome and loss of wellbeing (Hart, 2014) leaving no choice for the individual but to deceive himself or others (Kline \& Sulsky, 2009).

The process of conflict has five stages: incompatibility, cognition, intentions, behaviors and outcomes. The famous Thomas-Kilmann model (TK model) focuses on the third stage of conflict i.e. the intentions of resolving the conflict. The five intentions outlined in the TK model are: Avoiding, Competing, Accommodating, Compromising and Collaborating. The TK model places the five intentions on the Assertiveness and Cooperativeness axis (see figure 1). In a conflict situation, our intentions to resolve the conflict tend to translate 
into our actions (Kilmann \& Thomas, 1975). The intentions stage defines how the parties in the conflict want to resolve it, whether through competing or avoiding. Depending on their intentions the concerned parties can come up with a mutual solution (collaborate) or compromise their stand for the other party's benefit. Resolution of conflict may get influenced by the outside world i.e. environment and also the internal world i.e. our needs, feelings, hopes etc. In order to reach an agreement between the outside and the inside worlds, one may end up taking the route of deception (Triandis, 2015).

\section{Literature Review}

Deception can be defined in different ways, it can be in the form of self-deception, such as when an individual deliberately avoids an undesirable information (Mele, 1997), holds contradictory beliefs (Gur \& Sackeim, 1979), unknowingly sees things in a positive manner (Kurzban \& Athena Aktipis, 2007), initiates a biased set of knowledge (Trivers, 2010). Deception is further defined as an intentional manipulation or concealing of words, facts \& figures (Masip, Garrido, \& Herrero, 2004). Interestingly, deception, though taken as a negative attribute, has been found to facilitate individuals by keeping them motivated in situations where things are not going as per plan.

Deception becomes more important in a conflict situation because the outcome is uncertain and yet significant for both the parties. While using deception in a conflict situation, one can fake that conflict is resolved whereas in reality it gets more intense. Such resolution can cause cognitive dissonance (Festinger, 1962) and in order to avoid it we tend to rationalize our (inappropriate) actions or beliefs. While deceiving we tend to rationalize our deceptive acts (Wood, 2000) making it 'acceptable' and justifying as to why deceiving is appropriate in a conflict situation. A conflict situation can be of high significance because of the stress the conflict cause can harm one's physical \& mental being in addition to his relationship with people who are in that situation.

Conflict is most likely to occur between persons having a complex interest, conflict has both competitive and cooperative aspects (Kochan \& Verma, 1983; Walton \& McKersie, 1991). The competitive aspect promotes the conflict (Barki \& Hartwick, 2001) on the other hand the cooperative aspect compels parties to reach an agreement (Deutsch \& Krauss, 1962). Work place conflicts arise from opposing interests involving disagreement on goals, shortage of resources and frustration and result in decline of team performance (De Dreu \& Weingart, 2003; Jehn \& Mannix, 2001).

The significance of conflict in work life has been established by a number of studies in the areas of performance, decision making, communication, leadership and interpersonal/social aspects, (Adil et al., 2014; Longe, 2015; Dana, 2001). A more constructive and newer approach to conflict is to encourage conflicts and keeping it task focused which results in creativity (Robbins, 1974). Conflict situations invite everybody to voice their point of view and perspective. Hughes et al. (1993) claim that positive effects like enhanced understanding, feelings getting aired, better decision making could be outcomes of conflicts. Recently, Social media has been found to fan-up conflicts and political behavior as it influences one's socializing (Zeitzoff, 2017). A well-managed conflict at times 
requires some amount of deception by one or both the parties in order to reach a consensus. The conflicting parties must carry a flexible and open approach towards new ideas to resolve conflicts and must also be willing to take risks in the process of conflict resolution (Halperin \& Bar-Tal, 2011). Managers today need to come up with innovative conflict resolution strategies for trouble-free organizational environment (Abbas \& Karage, 2015; Prause \& Mujtaba, 2015). Our intentions in conflicting situations become more significant as they directly have an impact on the outcome of the conflict or any future dealing with the people involved in that situation (Robbins, 1974).

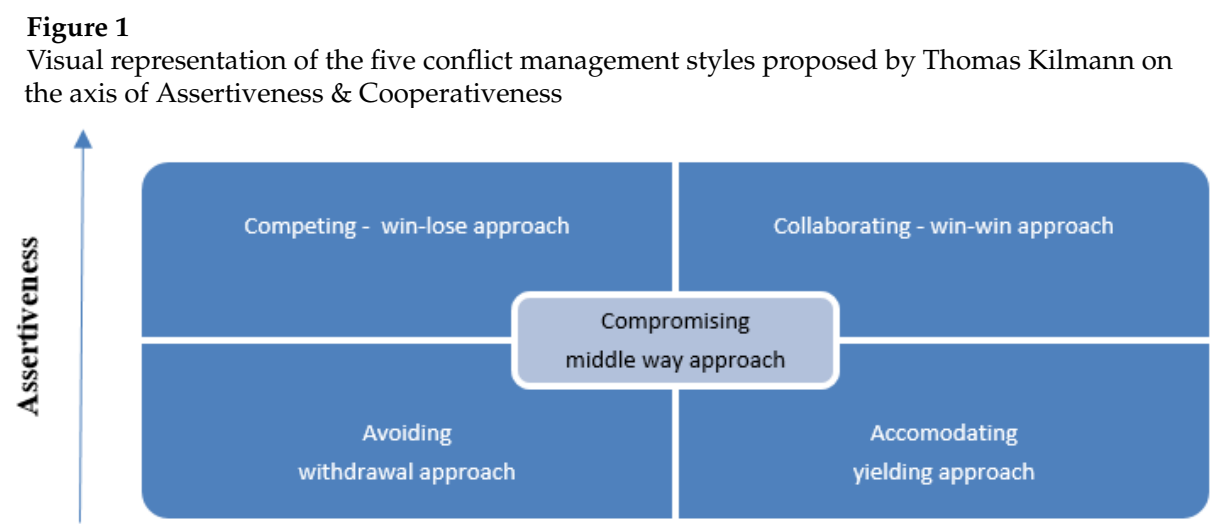

\section{Cooperativeness}

A broader deep intention encompassing all the above five intentions can be Deception. One can be engaged in deception in a conflict situation, while competing, avoiding, accommodating, compromising and collaborating (see Fig. I). One may pretend to resolve conflict but in the heart of the hearts the intention is to deceive the other party. The conflict may get resolved superficially only. The route of deception may not necessarily be a 'bad' route. Deception could also be seen as a social (political) skill very close to the concept of being diplomat in one's interactions (Clements, Boyle, \& Proudfoot, 2016). If both are parties are achieving their objectives while deceiving the outcome is a win-win situation. Machiavellianism personality attribute also indicates a high probability of use of exploitative and manipulative tactics (deception) when dealing with people (Amir \& Malik, 2016).

The reasons for using Deception as conflict resolution technique may be numerous. One possible one could be the fear of losing the desired outcome and that fear restrains people to resolve conflict. We may fear that by deceiving other party, we are actually saving ourselves of losing them. Deception can also be seen as a short term strategy where we may tend to pacify the other party by faking. The reasons for usage of deception can be mal intention on our part, where we intend to cheat the other party for our own benefit, we may tend to foresee unpleasant responses from the other party and on the basis of that we deceive them in resolution to avoid unpleasant outcome of the situation (Lee, Chung, 
\& Welker, 2018).

The outcomes of using deception in conflict resolution can be both positive and negative. Positive outcomes could be minimal unpleasantness between the parties, fewer possibilities of emotional outbursts, where diplomacy is the only way out and also when the conflict is so intense that no other technique is working. A possible negative outcome of the use of deception can be of the conflict converting into a grudge which may burst out in future, and which is likely to be more damaging for long term relationships. In a situation where both the parties tend to use deception as a technique to resolve conflict, the outcome could be more detrimental (Robbins, 1974).

The main objective of this research was to construct a scale that investigates humans' perceptions regarding the construct of deception and its usage in different contexts specifically general deception, deception in conflict management, self-deception, workplace deception, and interpersonal deception. In extension since perceptions may translate into actions (values) the responses on the scale would provide valuable insights regarding the probability of an individual in usage of deception. The study further aimed to establish psychometric properties of the developed scale (Simms, 2008). This scale aims to help individuals in gaining awareness on their own tendency and preference for deception usage. The scale constructed would convert behavioral construct of deception into numerical form which can then be interpreted to understand the possibility of use of deception and how it is viewed in personal and social contexts (DeVellis, 1991).

\section{Methodology}

A number of psychometric authors Clark and Watson (1995); DeVellis (2016); Hung and Petrick (2010) agreed that scale construction is a complex process having three main steps. The first step is what is commonly called item generation, where, the researcher provides the theoretical grounds for item pool (Vazquez, Magnan, Pacico, Hutz, \& Schaufeli, 2015). This can be done through the inductive or deductive approach. When existing literature and scales are used to develop a new measure, it is called deductive approach (Hinkin, 1995). Inductive approach is adopted in the development of Deception as Conflict Management Technique Scale (DCMTS), where qualitative information in the form of opinion about the construct is collected and later translated into numeric values (Kapuscinski \& Masters, 2010).

\section{Step 1: Item Generation}

The starting point in the development of the scale was to generate a pool of items encompassing the broader approach towards deception as a technique in social \& conflict settings. Initially random input was taken from a sample of people by asking them to provide one-word or one-line response of what comes to their minds when they hear the word 'deception'. 


\begin{abstract}
Figure 2
Steps followed in the development of the scale from Item generation to psychometric properties assessments.
\end{abstract}

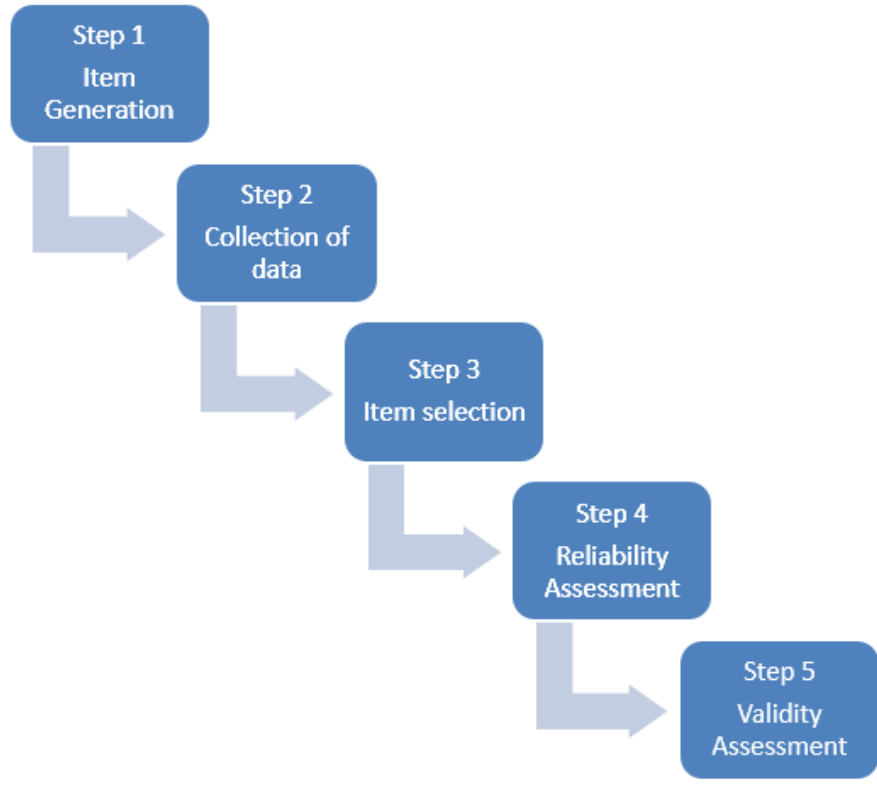

After that, in the light of the responses and the literature review, (Haynes, Richard, \& Kubany, 1995) the author generated a pool of 50-items on deception on five dimensions: general, self-deception, deception in conflict situation, interpersonal deception and deception at workplace. This pool of items then went through review by four subject experts - all PhD holders in the discipline of Psychology (Worthington \& Whittaker, 2006). This process resulted in improvement in item phrasing and expressions, removal of ambiguous and vagueness in items (Xu \& Tracey, 2015). This helped the researcher to check if the items fulfill the parameters of good item writing or not (Clark \& Watson, 1995). The input from the subject experts further assisted the researcher in framing the items appropriately specially to avoid the drawbacks of self-reporting, the questions were framed in terms of perceptual views, seeking respondents' opinion on the construct of deception. Despite the drawbacks of self-reporting method, it is still popular among psychologists because it generates greater number of responses in less cost, easy to calculate and considered as a direct method to gain insights and feelings of individuals (Simms \& Watson, 2007). The detailed procedure was followed as deception is a covert construct and hence difficult to bring it to the level of measurement (Crocker \& Algina, 1986; Kim, Atkinson, \& Yang, 1999).

The basic rules of item writing were followed by the researcher; the language was kept simple, clear, and straight forward and appropriate so that it could be understandable to a larger population (Brakus, Schmitt, \& Zarantonello, 2009; Furr, 2011). Thus, the negatively phrased expressions were avoided as were double-barreled \& slang expressions. It 
has been found in a number of studies that negatively and positively worded items tend to create measurement and interpretation errors which can effect the construct analysis as a whole (Quilty, Oakman, \& Risko, 2006; DiStefano \& Motl, 2006).

Next thing to be determined was the response category. Response categories can be either dichotomous (forced choice) or Likert type (multiple responses) with the scale developer deciding the number of choices to be given to the respondent. It has been found that multiple choice format produces more consistent results (Reise, Waller, \& Comrey, 2000). For DCMTS, a five point Likert scale seemed appropriate because the five options allowed perceptual measurement of the respondent for deep down intention of deception in a better manner. Lietz (2010) concluded that five or eight category responses in a Likert type scale is a well fit and suitable for questionnaires.

Further, the number of items on a scale also needed to be determined. Research revealed that a lengthy questionnaire could result in respondent fatigue, boredom, biased responses. The probability of having missing items and non-serious or patterned responses also increase with long questionnaires, whereas a shorter questionnaire can pose a reliability and validity threat (Kenny \& Harackiewicz, 1979). Keeping this in mind while developing the scale of Deception as Conflict Management Technique, the scale developer aimed for enough number of items without compromising on the scale's psychometric properties of validity and reliability (Cronbach \& Meehl, 1955; Roznowski, 1989).

\section{Step 2: Collection of Data}

For this step, the 50-item questionnaire was administered to a sample of 408 individuals using convenience sampling method. The scale assessed five different dimensions of the use of deception: general, self-deception, deception in conflict situation, interpersonal deception and deception at workplace. Responses were taken on a 5-point Likert scale from 'strongly disagree' to 'strongly agree' indicating degree of agreement or disagreement with the statements.

\section{Step 3: Item Selection}

For item selection, the collected data was analyzed. Through item-analysis $r$ values were calculated. Items with $r$ values greater than 0.25 were retained and the rest of the items were eliminated (Singh, 1986). The questionnaire was then reduced to 35-items.

\section{Step 4: Reliability Assessment}

The 35-item scale was ready for reliability assessment. To measure test consistency, the researchers commonly use test-retest reliability i.e. how reliable the test is over a period of time. In simple words, the same test is given to same people at two different times and if the scores are similar, the test is established as a reliable test giving consistent results.

For this study, test-retest reliability was chosen and the scale was administered on 103 respondents, selected through convenience sampling. After a gap of fifteen days, the second administration of the scale was done on the same respondents for retest process 
completion. Research supports that there is no set criteria for the time interval to be kept between the two administrations of the test (Marx, Menezes, Horovitz, Jones, \& Warren, 2003).

\section{Step 5: Construct Validity Assessment}

Construct validity defines how well a test measure what it claims to measure. Construct validity is established by comparing the test to other similar tests to see if both are highly correlated with each other. Construct validity is determined by two ways; firstly, through using tests which are supposed to measure similar constructs which is called convergent validity and secondly by using tests which measure opposite constructs which is called discriminant validity.

For the establishment of construct validity, both convergent and discriminant, the scale was administered on 135 respondents along with the existing established scales. For convergent validity, a scale was selected on the basis of similarity with the construct Deception. The selected scale was Self-Report Jealousy Scale. On the basis of having opposite construct of honesty, Perceived Honesty Scale was selected for discriminant validity assessment (Revelle, 2012). The battery of tests presented to the respondents and their responses were recorded.

\section{Sample}

There were three different samples for the completion of the steps of scale development. For the first item selection step there were 408 respondents. For the reliability and validity assessments, 103 and 135 respondents respectively were administered the scale. After the informed consent was taken, all the respondents were given assurance of confidentiality and that their participation was purely on a voluntary basis. The demographic details of all the three samples are provided in Table 1.

\section{Data Analysis}

The scoring of the initial 50-items was done using MS Excel and SPSS 21.0. Descriptive statistics, r values, inter-item correlation, for item total correlation, exploratory factor analysis and correlation values were calculated for authenticating the reliability and validity of the scale using SPSS 21.0.

Table 1 shows demographic information of all the respondents who participated in item selection $(n=408)$, reliability $(n=103)$ and validity assessments $(n=135)$. The data provides the frequency and percentages of the respondents' gender, age and education level.

Table 2 Shows the descriptive statistics and item total correlation of Item Pool of 50item of DCMTS. 
Table 1

Respondents' Demographics Information of all the three samples

\begin{tabular}{|c|c|c|c|c|c|c|c|}
\hline \multicolumn{2}{|c|}{ Demographic details for the 408 sample } & Frequency & $\begin{array}{c}\text { Percentage } \\
\%\end{array}$ & Frequency & $\begin{array}{c}\text { Percentage } \\
\%\end{array}$ & Frequency & $\begin{array}{c}\text { Percentage } \\
\%\end{array}$ \\
\hline & & \multicolumn{2}{|c|}{$n=408$} & \multicolumn{2}{|c|}{$n=103$} & \multicolumn{2}{|c|}{$\mathrm{n}=135$} \\
\hline \multirow[t]{2}{*}{ Gender } & Male & 127 & $31 \%$ & 45 & $43.70 \%$ & 59 & $43.70 \%$ \\
\hline & Female & 281 & $69 \%$ & 58 & $56.30 \%$ & 76 & $56.30 \%$ \\
\hline \multirow[t]{4}{*}{ Age } & 15-25 Years & 299 & $73.30 \%$ & 99 & $96.10 \%$ & 130 & $96.30 \%$ \\
\hline & 26-35 Years & 100 & $24.50 \%$ & 4 & $3.90 \%$ & 5 & $3.70 \%$ \\
\hline & $36-45$ Years & 9 & $2.20 \%$ & 0 & $0 \%$ & 0 & $0 \%$ \\
\hline & 46 or Above & 0 & $0 \%$ & 0 & $0 \%$ & 0 & $0 \%$ \\
\hline \multirow[t]{3}{*}{ Education } & Under Graduate & 169 & $41.40 \%$ & 96 & $93.20 \%$ & 122 & $90.40 \%$ \\
\hline & Graduate & 174 & $42.60 \%$ & 6 & $5.80 \%$ & 7 & $5.20 \%$ \\
\hline & Post Graduate & 65 & $16 \%$ & 1 & $1 \%$ & 6 & $4.40 \%$ \\
\hline
\end{tabular}

Table 2

Descriptive Statistics and Item total Correlations of Item Pool 50-item of Deception as Conflict Management Technique Scale

\begin{tabular}{lccccccccc}
\hline $\begin{array}{l}\text { Item } \\
\#\end{array}$ & $\mathbf{M}$ & SD & Item Total $\mathbf{r}$ & $\begin{array}{c}\text { Sig. } \\
\text { Item } \\
\#\end{array}$ & $\mathbf{M}$ & SD & Item Total r & Sig \\
\hline 1 & 3.48 & 0.994 & 0.217 & 0 & 26 & 3.44 & 1.064 & 0.366 & 0 \\
2 & 3.70 & 0.935 & 0.249 & 0 & 27 & 3.47 & 1.008 & 0.356 & 0 \\
3 & 2.63 & 1.168 & 0.148 & 0 & 28 & 3.63 & 1.259 & 0.345 & 0 \\
4 & 2.71 & 1.192 & 0.104 & 0 & 29 & 3.51 & 1.102 & 0.465 & 0 \\
5 & 3.06 & 1.045 & 0.154 & 0 & 30 & 3.78 & 1.023 & 0.457 & 0 \\
6 & 2.93 & 1.193 & 0.245 & 0 & 31 & 3.99 & 1.111 & 0.473 & 0 \\
7 & 2.91 & 1.096 & 0.106 & 0 & 32 & 3.59 & 1.017 & 0.328 & 0 \\
8 & 3.70 & 1.097 & 0.408 & 0 & 33 & 3.57 & 1.049 & 0.432 & 0 \\
9 & 3.55 & 0.957 & 0.414 & 0 & 34 & 3.50 & 0.991 & 0.358 & 0 \\
10 & 3.44 & 0.906 & 0.422 & 0 & 35 & 3.45 & 1.022 & 0.374 & 0 \\
11 & 3.34 & 1.010 & 0.321 & 0 & 36 & 3.82 & 1.074 & 0.512 & 0 \\
12 & 3.51 & 1.042 & 0.392 & 0 & 37 & 3.99 & 1.013 & 0.510 & 0 \\
13 & 2.82 & 1.112 & 0.101 & 0 & 38 & 3.91 & 1.105 & 0.493 & 0 \\
14 & 2.81 & 0.974 & 0.114 & 0 & 39 & 3.37 & 1.159 & 0.265 & 0 \\
15 & 2.91 & 1.025 & 0.164 & 0 & 40 & 3.64 & 1.145 & 0.479 & 0 \\
16 & 3.63 & 0.990 & 0.457 & 0 & 41 & 3.52 & 1.090 & 0.419 & 0 \\
17 & 3.85 & 1.249 & 0.457 & 0 & 42 & 3.61 & 1.065 & 0.380 & 0 \\
18 & 2.96 & 1.215 & 0.215 & 0 & 43 & 3.51 & 1.079 & 0.490 & 0 \\
19 & 3.06 & 1.184 & 0.192 & 0 & 44 & 3.63 & 0.985 & 0.506 & 0 \\
20 & 3.99 & 1.249 & 0.442 & 0 & 45 & 3.65 & 1.103 & 0.514 & 0 \\
21 & 3.47 & 1.126 & 0.303 & 0 & 46 & 3.67 & 1.041 & 0.448 & 0 \\
22 & 2.80 & 1.151 & 0.078 & 0 & 47 & 3.33 & 0.946 & 0.295 & 0 \\
23 & 3.33 & 1.052 & 0.355 & 0 & 48 & 3.16 & 1.133 & 0.125 & 0 \\
24 & 3.25 & 1.086 & 0.294 & 0 & 49 & 3.53 & 1.015 & 0.198 & 0 \\
25 & 3.57 & 0.989 & 0.403 & 0 & 50 & 3.20 & 1.136 & 0.228 & 0 \\
\hline & & & & & & & & &
\end{tabular}

Table 3

Reliability Analysis- Scale (Alpha) for

Deception as Conflict Management

Technique Scale

\begin{tabular}{lc}
\hline Cronbach's & Items \\
\hline Alpha & $(\mathrm{N})$ \\
0.896 & 35 \\
\hline
\end{tabular}


Table 3 shows reliability analysis of Deception as Conflict Management Technique Scale of selected items. $\mathrm{N}=408$

Table 4

Cronbach Alpha values of the Five Sub scales with number of items per sub scale

\begin{tabular}{lcc}
\hline Sub Scale & No. of items & Cronbach Alpha \\
\hline 1. General Deception & 9 & 0.677 \\
2. Deception in Conflict Management & 11 & 0.718 \\
3. Self-Deception & 4 & 0.506 \\
4. Deception at workplace & 2 & 0.462 \\
5. Interpersonal Deception & 17 & 0.720 \\
\hline
\end{tabular}

Table 4 shows Cronbach alpha values for the five sub-scales of DCMTS along with item numbers, where Interpersonal Deception shows the highest Cronbach alpha value of .720. $\mathrm{N}=408$

\begin{tabular}{|c|c|c|c|}
\hline Component & Eigenvalues & Component & Eigenvalues \\
\hline 1 & 8.310 & 19 & 0.691 \\
\hline 2 & 2.197 & 20 & 0.678 \\
\hline 3 & 1.930 & 21 & 0.662 \\
\hline 4 & 1.397 & 22 & 0.615 \\
\hline 5 & 1.257 & 23 & 0.603 \\
\hline 6 & 1.194 & 24 & 0.556 \\
\hline 7 & 1.175 & 25 & 0.551 \\
\hline 8 & 1.115 & 26 & 0.521 \\
\hline 9 & 1.061 & 27 & 0.516 \\
\hline 10 & 1.029 & 28 & 0.496 \\
\hline 11 & 0.979 & 29 & 0.488 \\
\hline 12 & 0.937 & 30 & 0.440 \\
\hline 13 & 0.915 & 31 & 0.434 \\
\hline 14 & 0.881 & 32 & 0.424 \\
\hline 15 & 0.846 & 33 & 0.393 \\
\hline 16 & 0.822 & 34 & 0.374 \\
\hline 17 & 0.768 & 35 & 0.369 \\
\hline 18 & 0.734 & & \\
\hline
\end{tabular}

Table 5 shows extraction method for EFA with principle component analysis where cutoff Eigenvalues were set at 1 which extracted 10 factors for DCMTS - 35-items. N=408

Table 6 shows Variance explained percentage of 10 extracted factors and item loading for items in each factor of DCMTS. 


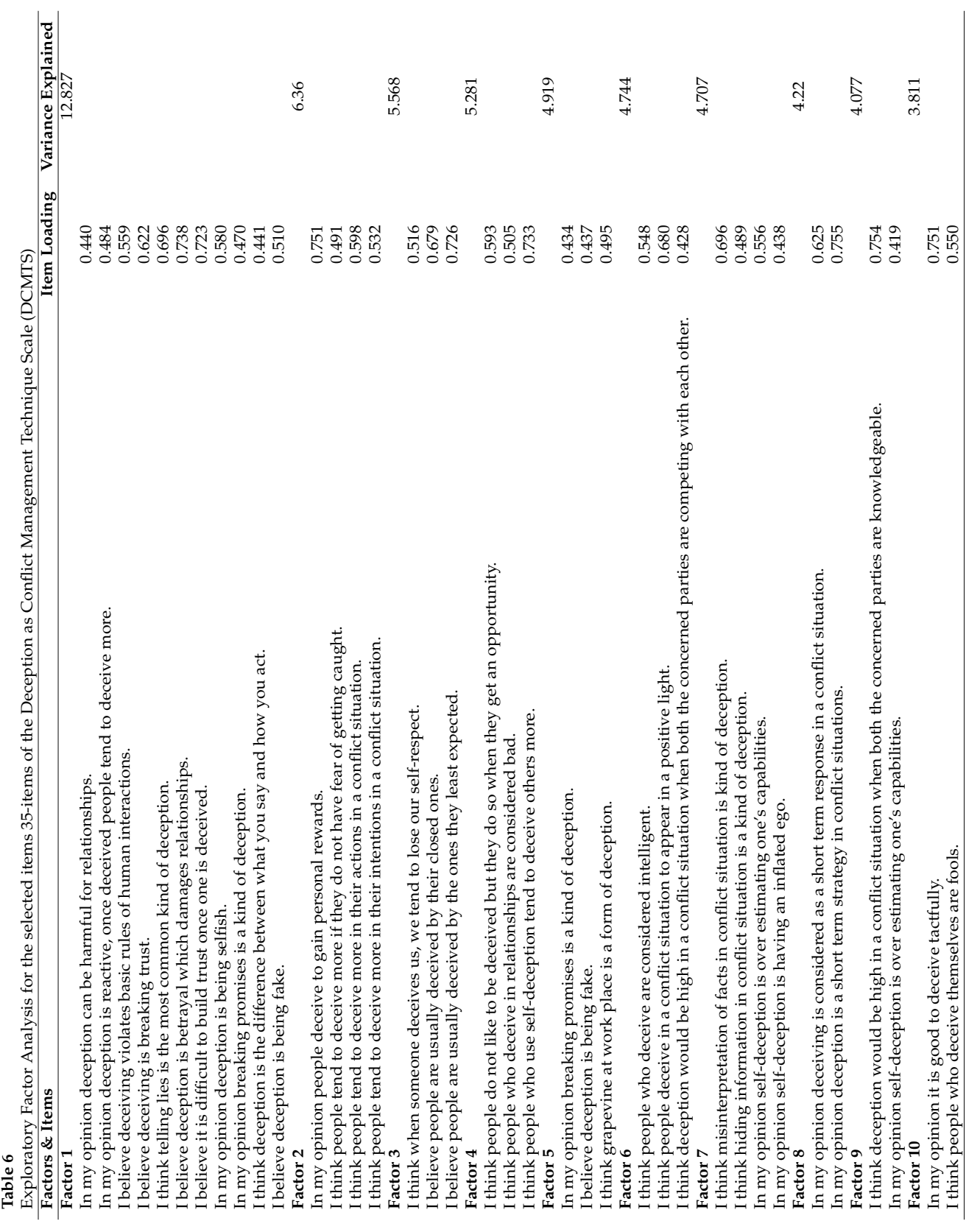




\section{Figure 3}

Screen plotting of 36-item DCMTS through Exploratory Factor Analysis

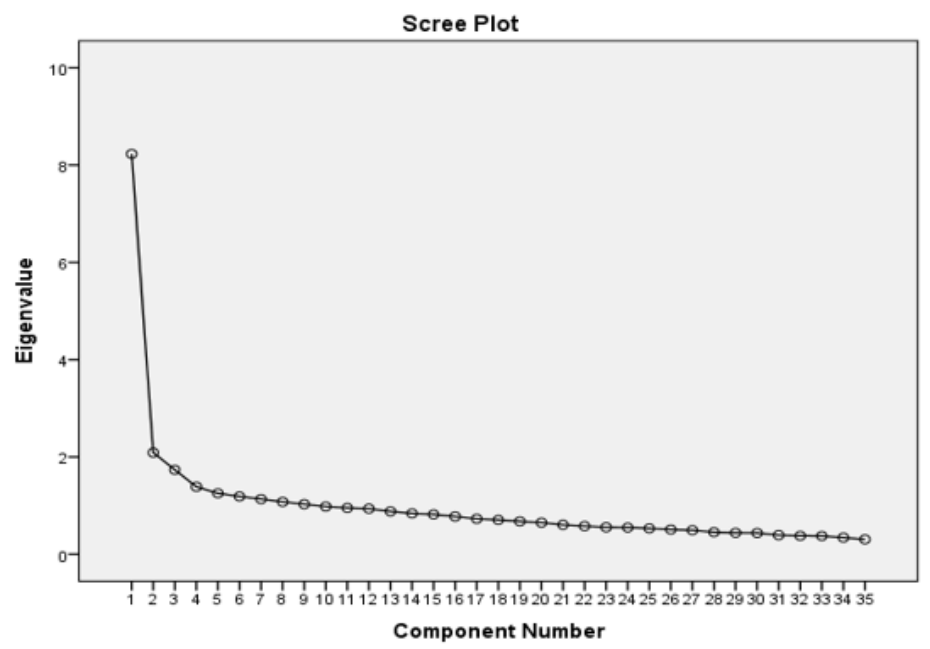

Table 7

Correlation values of Administration 1 and Administration 2 for

Test-Retest Reliability of Deception as Conflict Management Technique Scale (DCMTS)

\begin{tabular}{lcc}
\hline & & Administration 2 \\
\hline Administration 1 & Pearson Correlation & $.832^{* *}$ \\
& Sig. (2-tailed) & 0 \\
\hline$* *$ Correlation is significant at the 0.01 level (2-tailed). $\mathrm{n}=103$
\end{tabular}

Table 7 showing correlation value calculated at .832 of test-retest reliability of Deception as Conflict Management Technique Scale (DCMTS).

Table 8

Correlation values for establishing Convergent and Discriminant Validity of Deception as Conflict Management Technique Scale (DCMTS)

\begin{tabular}{lccc}
\hline & & DCMTS \\
\hline Convergent Validity & $\begin{array}{c}\text { Self-Report Jealousy Scale } \\
\text { (SRJS) }\end{array}$ & Pearson Correlation & $.724^{* *}$ \\
& & Sig. (2-tailed) & 0.000 \\
Discriminant Validity & Perceived Honesty Scale & $\begin{array}{c}\text { Pearson Correlation } \\
\text { Sign. (2-tailed) }\end{array}$ & $\begin{array}{c}.718^{* *} \\
0\end{array}$ \\
\hline & & 0.01 level (2-tailed). $\mathrm{n}=135$
\end{tabular}

Table 8 showing Correlation values of two scales for establishing convergent validity and one scale with DCMTS for discriminant validity. Statistical values show that a positive correlation of .724 with Self-Report Jealousy Scale with DCMTS. For the discriminant validity, a correlation value of .718 is reported for Perceived Honesty Scale with DCMTS. 


\section{Discussion}

The purpose of the study was to develop a tool to measure individual's perceptions on deception in general and specifically as a conflict management technique and the likelihood of its usage by individuals on the basis of their perceptions. As a continuation of this purpose, the next goal was to test and ascertain the validity and reliability of the instrument. The final developed scale has 35 items with five sub-scales: general deception, deception in conflict management, self-deception, interpersonal deception and deception at workplace. The format of responses has been kept on a 5-point Likert scale from strongly agree to strongly disagree.

The 35 items have been selected from the item pool of 50-items through item total correlation. The criterion for the selection of items was 0.05 levels and 36 items were found significant at 0.01 level. The calculated Pearson Product Moment correlation values were not found significant for these items: 1, 3, 4, 5, 7, 13, 14, 15, 18, 19, 22, 48, 49 and 50 . For the remaining 36 items, the $r$ values were significant as they were above 0.250 (see Table 2). Items 36, 37, 44 and 45 were found to be highly significant with high $r$ values. The criterion followed for selection of items was 0.250 (Singh, 1986). Out of the selected 36-items, Item 11 and Item 27 were found to be measuring very similar construct so item 11 was also discarded and Item 27 was kept on the basis of higher $r$ value, which reduced the final selected items to 35 . Table 2 also provides the descriptive statistics of means \& standard deviations of the 50 -item pool of DCMTS.

To determine the internal consistency of the scale, Cronbach alpha was calculated for the total score of the 408 respondents on selected 35 items which reported at 0.896 (see Table 3). The significant alpha value shows that all items are internally consistent and the scale is significant to be used for research (Nunnally \& Bernstein, 1967; O'Rourke, Hatcher, \& Stepanski, 2005) and in general to measure use of deception in all five variables. Further Cronbach alpha values were calculated for the five sub-scales (see Table 4), which indicates that all items are related to the same construct and are highly reliable and consistent. A high Cronbach alpha values signifies that the items of the scale are measuring same construct (Tavakol \& Dennick, 2011). A consensus on the acceptable alpha range value is from 0.70-0.95 (Streiner, 2003; Tavakol \& Dennick, 2011). The maximum acceptable value is 0.90 (Tavakol \& Dennick, 2011). A low alpha value indicates a not-so-good inter-relatedness between the items of the scale or that the scale has a variety of constructs which are being measured and hence lack relatedness. Whereas a very high alpha value directs towards redundancy of the items i.e. items are measuring the same question with a different phrasing only.

Exploratory Factor Analysis was carried out using principal component method as the study aimed to develop a new instrument for deception (Thompson, 2004). Using Varimax rotation which is most commonly used rotation in order to enhance the psychometric properties of reliability and validity (Preacher \& MacCallum, 2003). Ten factors were extracted (see Table 5) giving Eigenvalues where cut off was set at 1 . The 35 -items were reduced to ten factors and item loading and variance explained is calculated (see Table 6). The total explained variance was 31.759 percent. Ten factors were sorted out of thirty six items, where item 11 was dropped and item 27 retained on the basis of similarity in 
construct measuring reducing the scale to 35 -items. The criteria for factor loading is 40 (Sax, 1997), the item loading for DCMTS reports highest .755 to lowest at .419 (see Table 6).

The next step after item selection was to establish psychometric properties of reliability and validity for the scale. For reliability analysis, test-retest reliability was carried out and the calculated coefficient of reliability was .832 ( $\mathrm{p}<.001)$, which is the acceptable internal consistency value signifying scale stability (see Table 7).

The last step was of determining construct validity of the scale. To ascertain the convergent validity of DCMTS, correlations with an existing scale was calculated and reported in Table 8. Pearson correlation value for Self-Report Jealousy Scale with DCMTS was .724 ( $\mathrm{p}<.001)$ which is highly significant. For discriminant validity, Pearson correlation value was calculated for the selected existing scale: Perceived Honesty Scale, calculated values are reported in Table 8. Pearson correlation value for Perceived Honesty Scale correlation value was $.718(\mathrm{p}<.001)$, which is significant.

Some limitations of the study could be that the data collection was done through selfreported measure which has a risk of respondents being biased in their responses specifically, the social desirability effect can limit the true responses. Another limitation can be that the data was only collected from Karachi (Pakistan). In the future, data can be collected from the other cities of Pakistan to determine whether the construct is the same or it changes according to culture. The items 2 and 6 with weak correlation values may need to be reframed and modified for future research.

The DCMTS tool has found to be significant in quantifying the perceptions and accordingly predicting its usage. However, one must consider that the use of deception technique in general or conflict settings could be influenced by some individual and social factors which may need further elaboration.

\section{Conclusion}

Deception as Conflict Management Technique Scale has been scientifically developed and will be a useful tool for researchers whose area of interest is in exploring the factors related to the construct of deception. The study was carried out in five steps; from item generation to establishment of psychometric properties of reliability \& validity. The developed 35-item tool reported Cronbach's alpha value of .896 which shows internal consistency. Cronbach's alpha values were significant for the five sub scales: General Deception, Deception in Conflict Situation, Self-Deception, Interpersonal Deception and Deception at workplace. Through test-retest reliability DCMTS has been established as a reliable tool with reported correlation value of .832 , which is significant. Construct validity of the tool was verified by using existing scales for convergent and discriminant validity. Significant correlation values for construct validity proved DCMTS as a valid tool for deception.

The tool can be used in the areas of organizational and social psychology to measure the perception and, further, the probable use of deception in conflict setting, workplace and interpersonal deception. Though the initial findings resulted in the development of a sound and effective tool on deception, future studies are needed to strengthen the tool 
specially in different cultures. Further studies can be carried out in the future which can incorporate the use of qualitative measures like focus groups or interviews for an in-depth analysis of the construct of deception. 


\section{References}

Abbas, S. S., \& Karage, A. I. (2015). Workplace conflict management styles: Comparative study of Indian and Nigerian employees. European Journal of Business and Management, 7(23), 44-54.

Adil, M. S., et al. (2014). Impact of leader's change-promoting behavior on readiness for change: A mediating role of organizational culture. Journal of Management Sciences, 1(2), 102-123.

Amir, T. S., \& Malik, A. A. (2016). Machiavellianism and counterproductive behaviors at workplace. Journal of Education $\mathcal{E}$ Social Sciences, 4(1), 14-29.

Bacharach, S. B., \& Lawler, E. J. (1981). Bargaining: Power, tactics and outcomes. San Francisco: Jossey-Bass Inc.

Barki, H., \& Hartwick, J. (2001). Interpersonal conflict and its management in information system development. Mis Quarterly, 25(2), 195-228.

Brakus, J. J., Schmitt, B. H., \& Zarantonello, L. (2009). Brand experience: what is it? how is it measured? does it affect loyalty? Journal of Marketing, 73(3), 52-68.

Churchill Jr, G. A. (1979). A paradigm for developing better measures of marketing constructs. Journal of Marketing Research, 64-73.

Clark, L. A., \& Watson, D. (1995). Constructing validity: Basic issues in objective scale development. Psychological Assessment, 7(3), 309-319.

Clements, J. A., Boyle, R., \& Proudfoot, J. G. (2016). Exploring political skill and deception. International Journal of Sociology and Social Policy, 36(3/4), 138-156.

Crocker, L., \& Algina, J. (1986). Introduction to classical and modern test theory. Orlando: Holt, Rinehart and Winston.

Cronbach, L. J., \& Meehl, P. E. (1955). Construct validity in psychological tests. Psychological Bulletin, 52(4), 281-302.

Dana, D. (2001). Managing differences: How to build better relationships at work and home. MTI publications.

De Dreu, C. K., \& Weingart, L. R. (2003). Task versus relationship conflict, team performance, and team member satisfaction: a meta-analysis. Journal of Applied Psychology, 88(4), 741-749.

Deutsch, M., \& Krauss, R. M. (1962). Studies of interpersonal bargaining. Journal of Conflict Resolution, 6(1), 52-76.

DeVellis, R. F. (1991). Applied social research methods series, scale development: Theory and applications. USA: Thousand Oaks.

DeVellis, R. F. (2016). Scale development: Theory and applications. Sage publications.

Devine, D. J., Clayton, L. D., Philips, J. L., Dunford, B. B., \& Melner, S. B. (1999). Teams in organizations: Prevalence, characteristics, and effectiveness. Small Group Research, 30(6), 678-711.

DiStefano, C., \& Motl, R. W. (2006). Further investigating method effects associated with negatively worded items on self-report surveys. Structural Equation Modeling, 13(3), 440-464.

Ekman, P. (2009). Lie catching and microexpressions. The Philosophy of Deception, 118-133. 
Feldman, R. S., Forrest, J. A., \& Happ, B. R. (2002). Self-presentation and verbal deception: Do self-presenters lie more? Basic and Applied Social Psychology, 24(2), 163-170.

Festinger, L. (1962). A theory of cognitive dissonance. Stanford university press.

Freud, S. (2014). The neuro-psychoses of defence. Read Books Ltd.

Furnham, A. (2012). Lay understandings of defence mechanisms: The role of personality traits and gender. Psychology, Health \& Medicine, 17(6), 723-734.

Furr, M. (2011). Scale construction and psychometrics for social and personality psychology. SAGE Publications Ltd.

Gur, R. C., \& Sackeim, H. A. (1979). Self-deception: A concept in search of a phenomenon. Journal of Personality and Social Psychology, 37(2), 147-169.

Halperin, E., \& Bar-Tal, D. (2011). Socio-psychological barriers to peace making: An empirical examination within the Israeli Jewish society. Journal of Peace Research, 48(5), 637-651.

Hart, J. (2014). Toward an integrative theory of psychological defense. Perspectives on Psychological Science, 9(1), 19-39.

Haynes, S. N., Richard, D., \& Kubany, E. S. (1995). Content validity in psychological assessment: A functional approach to concepts and methods. Psychological Assessment, 7(3), 238-247.

Hinkin, T. R. (1995). A review of scale development practices in the study of organizations. Journal of Management, 21(5), 967-988.

Hirsh, J. B., \& Kang, S. K. (2016). Mechanisms of identity conflict: Uncertainty, anxiety, and the behavioral inhibition system. Personality and Social Psychology Review, 20(3), 223-244.

Hughes, R. L., et al. (1993). Leadership: Enhancing the lessons of experience. Boston: McGraw Irwin.

Hung, K., \& Petrick, J. F. (2010). Developing a measurement scale for constraints to cruising. Annals of Tourism Research, 37(1), 206-228.

Jehn, K. A., \& Mannix, E. A. (2001). The dynamic nature of conflict: A longitudinal study of intragroup conflict and group performance. Academy of Management Journal, 44(2), 238-251.

Kapuscinski, A. N., \& Masters, K. S. (2010). The current status of measures of spirituality: A critical review of scale development. Psychology of Religion and Spirituality, 2(4), 191-205.

Kenny, D. A., \& Harackiewicz, J. M. (1979). Cross-lagged panel correlation: Practice and promise. Journal of Applied Psychology, 64(4), 372-379.

Kilmann, R. H., \& Thomas, K. W. (1975). Interpersonal conflict-handling behavior as reflections of Jungian personality dimensions. Psychological Reports, 37(3), 971-980.

Kim, B. S., Atkinson, D. R., \& Yang, P. H. (1999). The asian values scale: Development, factor analysis, validation, and reliability. Journal of Counseling Psychology, 46(3), 342-352.

Kline, T. J., \& Sulsky, L. M. (2009). Measurement and assessment issues in performance appraisal. Canadian Psychology/Psychologie Canadienne, 50(3), 161-171.

Kochan, T. A., \& Verma, A. (1983). Negotiations in organizations: Blending industrial relations and organizational behavior approaches (Unpublished doctoral dissertation). 
Kurzban, R., \& Athena Aktipis, C. (2007). Modularity and the social mind: Are psychologists too self-ish? Personality and Social Psychology Review, 11(2), 131-149.

Lee, C.-C., Chung, T., \& Welker, R. B. (2018). Behavioral genetics of deception detection performance. Journal of Managerial Psychology, 33(1), 106-120.

Lietz, P. (2010). Research into questionnaire design. International Journal of Market Research, 52(2), 249-272.

Longe, O. (2015). Impact of workplace conflict management on organizational performance: A case of nigerian manufacturing firm. Journal of Management and Strategy, 6(2), 83. doi: 10.5430/jms.v6n2p83

Marx, R. G., Menezes, A., Horovitz, L., Jones, E. C., \& Warren, R. F. (2003). A comparison of two time intervals for test-retest reliability of health status instruments. Journal of Clinical Epidemiology, 56(8), 730-735.

Masip, J., Garrido, E., \& Herrero, C. (2004). Defining deception. Anales de Psicología/Annals of Psychology, 20(1), 147-172.

Mele, A. R. (1997). Real self-deception. Behavioral and Brain Sciences, 20(1), 91-102.

Nunnally, J. C., \& Bernstein, I. H. (1967). Psychometric theory. McGraw-Hill New York.

O’Rourke, N., Hatcher, L., \& Stepanski, E. J. (2005). A step-by-step approach to using sas for univariate $\mathcal{E}$ multivariate statistics. SAS institute.

Pietromonaco, P. R., \& Barrett, L. F. (2000). The internal working models concept: What do we really know about the self in relation to others? Review of General Psychology, $4(2), 155-175$.

Prause, D., \& Mujtaba, B. G. (2015). Conflict management practices for diverse workplaces. Journal of Business Studies Quarterly, 6(3), 13-22.

Preacher, K. J., \& MacCallum, R. C. (2003). Repairing tom swift's electric factor analysis machine. Understanding Statistics: Statistical Issues in Psychology, Education, and the Social Sciences, 2(1), 13-43.

Quilty, L. C., Oakman, J. M., \& Risko, E. (2006). Correlates of the rosenberg self-esteem scale method effects. Structural Equation Modeling, 13(1), 99-117.

Reise, S. P., Waller, N. G., \& Comrey, A. L. (2000). Factor analysis and scale revision. Psychological Assessment, 12(3), 287.

Revelle, W. (2012). Psychometric theory: Scale construction. USA: Springer.

Robbins, S. P. (1974). Managing organizational conflict englewood cliffs. NJ: Prentice Hall.

Robie, C., Tuzinski, K. A., \& Bly, P. R. (2006). A survey of assessor beliefs and practices related to faking. Journal of Managerial Psychology, 21(7), 669-681.

Rogers, C. (2008). Carl rogers. New World Encyclopedia online.

Rogers, C. R. (1959). Significant learning in therapy and in education. Educational Leadership, 16(4), 232-242.

Roznowski, M. (1989). Examination of the measurement properties of the job descriptive index with experimental items. Journal of Applied Psychology, 74(5), 805.

Sax, G. (1997). Principles of educational and psychological measurement and evaluation. California: Wadsworth publishing company.

Serota, K. B., Levine, T. R., \& Boster, F. J. (2010). The prevalence of lying in america: Three studies of self-reported lies. Human Communication Research, 36(1), 2-25. 
Siefert, C., \& Porcerelli, J. (2015). Object relations theories and personality disorders: Internal representations and defense mechanisms. American Psychological Association Washington, DC.

Simms, L. J. (2008). Classical and modern methods of psychological scale construction. Social and Personality Psychology Compass, 2(1), 414-433.

Simms, L. J., \& Watson, D. (2007). The construct validation approach to personality scale construction.

Singh, A. K. (1986). Tests, measurements and research methods in behavioural sciences. Tata McGraw-Hill.

Stephen, D. G., Dixon, J. A., \& Isenhower, R. W. (2009). Dynamics of representational change: Entropy, action, and cognition. Journal of Experimental Psychology: Human Perception and Performance, 35(6), 1811-1832.

Streiner, D. L. (2003). Starting at the beginning: An introduction to coefficient alpha and internal consistency. Journal of Personality Assessment, 80(1), 99-103.

Tavakol, M., \& Dennick, R. (2011). Making sense of cronbach's alpha. International Journal of Medical Education, 2, 53-55.

Thompson, B. (2004). Exploratory and confirmatory factor analysis: Understanding concepts and applications. American Psychological Association.

Triandis, H. C. (2015). Culture and conflict. International Journal of Psychology, 35(2), $145-152$.

Trivers, R. (2010). Deceit and self-deception. Berlin: Springer.

Vazquez, A. C. S., Magnan, E. d. S., Pacico, J. C., Hutz, C. S., \& Schaufeli, W. B. (2015). Adaptation and validation of the Brazilian version of the Utrecht work engagement scale. Psico-USF, 20(2), 207-217.

Vrij, A., Akehurst, L., \& Knight, S. (2006). Police officers', social workers', teachers' and the general public's beliefs about deception in children, adolescents and adults. Legal and Criminological Psychology, 11(2), 297-312.

Walton, R. E., \& McKersie, R. B. (1991). A behavioral theory of labor negotiations: An analysis of a social interaction system. Cornell University Press.

Weiss, B., \& Feldman, R. S. (2006). Looking good and lying to do it: Deception as an impression management strategy in job interviews. Journal of Applied Social Psychology, 36(4), 1070-1086.

Wood, W. (2000). Attitude change: Persuasion and social influence. Annual Review of Psychology, 51(1), 539-570.

Worthington, R. L., \& Whittaker, T. A. (2006). Scale development research: A content analysis and recommendations for best practices. The Counseling Psychologist, 34(6), 806-838.

Xu, H., \& Tracey, T. J. (2015). Career decision ambiguity tolerance scale: Construction and initial validations. Journal of Vocational Behavior, 88, 1-9.

Zeitzoff, T. (2017). How social media is changing conflict. Journal of Conflict Resolution, 61(9), 1970-1991.

Zhang, W., \& Guo, B.-y. (2017). Resolving defence mechanisms: A perspective based on dissipative structure theory. The International Journal of Psychoanalysis, 98(2), 457472. 
Zuckerman, M., Koestner, R., \& Driver, R. (1981). Beliefs about cues associated with deception. Journal of Nonverbal Behavior, 6(2), 105-114. 